\title{
IMPROVING STATE SUPPORT FOR THE LIVESTOCK SECTOR IN THE RUSSIAN MACROECONOMIC INSTABILITY: PROBLEMS AND PROSPECTS (ON THE EXAMPLE OF DAIRY FARMING IN THE SARATOV REGION)
}

Bryzgalina Maya Anatolyevna, Post-graduate Student of the chair "Marketing and Foreign Economic Activity", Saratov State Agrarian University named after N.I. Vavilov; Junior Researcher, Volga Research Institute for Economics and Organization of Agro-industrial Complex. Russia.

Keywords: state support; livestock breeding; dairy farming; Saratov region; World Trade Organization.

It is regarded the modern state support for animal husbandry in the Saratov region. It has been analyzed the dynamics of the existing forms of livestock subsidies in the region, as well as their distribution by boxes in accordance with WTO rules. It has been revealed a possible reserve of increasing figure of revenue from sales of dairy cattle breeding products, and thus, of improving the financial position of agricultural producers engaged in milk production. It is proposed a mechanism of transformation of one of the existing forms of industry subsidies from the "amber box" to the "green one" in accordance with WTO rules, as well as the optimization model aimed at the determining the required amount of state subsidies for the implementation of the proposed project in the dairy farming, including determination of the optimal quantity of breeding stock in the Saratov region.

\section{ИНФОРМАЦИОННОЕ ОБЕСПЕЧЕНИЕ БИЗНЕСА В СОВРЕМЕННЫХ УСЛОВИЯХ}

Удк 330.3

\section{РОМАШКИН Тимур Владимирович, Саратовский национальный государственный} университет имени Н.Г. Чернышевского

В статье анализируется один из актуальных вопросов предпринимательской деятельности, а именно информащионная составляющая бизнеса. Сфера бизнеса в современных условиях является центральным и существенным по объему сектором информационного рынка. Цель статьи - рассмотреть информационное обеспечение бизнеса российской действительности. Отмечено, ито информация в электронном оформлении является значимым компонентом рыночной инфраструктуры. Обосновано, ито неразвитость инфраструктуры информационного обслуживания бизнеса в России свидетельствует о незрелости российского бизнеса, об отсутствии аналитической работы, и, следовательно, низкой конкурентоспособности. Выявлены баръеры, препятствующие развитию российского рынка ИТ. Выделены перспективные конкурентные сферы российского ИТ-бизнеса и предложены направления совершенствования российского рынка информационных технологий ведения бизнеса. Основные положения и выводы обогащают теорию информационного рынка и позволяют сформировать эффективные инструменты реализации информационного обеспечения бизнеса с иелью его стабильного развития.

Сановление и эволюция информационных ресурсов осуществляется под воздействием огромного количества факторов [6], при этом главным толчком к становлению информационного производства и бизнеса является конкуренция производителей на рынке. Несомненно, что рыночная инфраструктура должна развиваться комплексно и быть адекватной происходящим изменениям. Для нее должно быть характерно внедрение институциональных инноваций - повышение доступности кредитных ресурсов для малых предприятий на основе клиентоориентированного подхода, применение форвардных сделок и товарного кредита, упрощение процедуры листинга для малых предприятий, дающего возможность их участия в биржевой торговле. России нужна инфраструктура рынка, позволяющая давать ежедневную информацию о движении цен и определять тенденции, а также необходим открытый доступ к фундаментальным, новостным и погодным факторам [7].

От информационной составляющей бизнеса на современном этапе зависят дальнейшее развитие предприятия, эффективное функционирование производственного процесса, место товаров на рынке и т.д. Можно сказать, что без информационного обеспечения бизнес обречен на провал, так как именно с помощью вовремя поступившей информации можно принять необходимое решение и оценить условия производства. 
С целью увеличения прибыли производители постоянно усовершенствуют информационное обеспечение бизнеса с тем чтобы «обойти» конкурентов. Соответственно в производстве появляются технически сложные приборы и материалы, его развитие обеспечивают дорогие научные исследования. Это ведет к повышению квалификации бизнесменов. Естественно постоянный рост образовательного уровня требует качественного информационного обеспечения специалистов.

В настоящее время в России нельзя говорить о высоком уровне развития информационного рынка: развиваются лишь отдельные информационные пространства. Работа ведется на федеральном, региональном и муниципальном уровнях. Сейчас можно только завидовать разнообразию информационного обслуживания в зарубежных странах и отечественный предприниматель вынужденно переплачивает российским поставщикам за услуги спорного качества. Однако растущий спрос и конкуренция подталкивают процесс развития рынка к уровню мирового стандарта.

Применениеинформационныхтехнологий в разных видах деятельности ведет к экономическому росту и социальному прогрессу современных государств. Россия добилась в этой сфере определенных успехов, однако уступает развитым странам. Для того чтобы увидеть картину информационного общества Всемирный экономический форум (World Economic Forum) ежегодно опубликовывает Индекс сетевой готовности (Networked Readiness Index), который показывает уровень развития информационно-коммуникационных технологий в мире. По данным Всемирного экономического форума (ВЭФ), в 2014 г. Россия заняла 50-е место среди стран мира по уровню развития информационно-коммуникационных технологий (The Networked Readiness Index), поднявшись на 4 строчки в этом рейтинге по сравнению с предыдущим годом [2]. Хотя среди стран БРИК это лучший показатель, он ниже чем результаты таких стран, как Азербайджан, Эстония, Литва, Казахстан и Латвия. При составлении рейтинга информационного развития ВЭФ учитывает наличие у населения навыков использования ИТ, доступность инфраструктуры, степень использования ИТ государством, бизнесом и частными лицами в стране. В рейтинге конкурентоспособности (The Global Competitiveness Index 2014-2015) Россия заняла 53-е место, поднявшись за год на 11 позиций [2].

В настоящее время Россия приблизилась к быстро растущим странам в области про- даж высокотехнологичных продуктов и услуг, но у нее есть ограничения для развития ИТ-сектора, а именно:

низкая платежеспособность населения; незначительный экономический рост;

застой в сфере развития малого, а так же среднего бизнеса;

минимальное количество информационно-активных потребителей;

слабая информационная культура общества и бизнеса;

финансовая зависимость ИТ-отрасли от уровня цен на нефть и газ на мировом рынке.

В чем главные причины отставани ВЭФ российского рынка ИТ от мировых стран? Это неготовность предприятий вкладывать инвестиции в ИТ-проекты и низкий уровень жизни населения [1]. ИТ отрасли в России не развивается как по причине неразвитости внутреннего законодательства в сфере ИТ, так и низкого спроса на ИТ со стороны потребителей: государства, населения, а также предприятий.

На сегодняшний день в данной сфере можно выделить следующие проблемы институционального характера:

отсутствие механизмов привлечения финансов;

низкое развитие телекоммуникационных инфраструктур;

несоответствие уровня профессионализма сотрудников в области информационных технологий мировым стандартам;

непредусмотренность механизмов для эффективного функционирования законодательства в области интеллектуальной собственности.

Предприятия отрасли информационных технологий не в состоянии самостоятельно решить вышеуказанные проблемы. Для этого необходима скоординированная государственная политика, направленная на сокращение вышеперечисленных барьеров, а также гарантированная поддержка со стороны государства информационному рынку в России. Развитие информационных технологий повлечет совершенствование системы образования и здравоохранения, что приведет к повышению компьютерной грамотности всего населения.

Рост бизнеса в России в начале XXI в. связан с развитием рынка информационных технологий. В соответствии с данными аналитического агентства IDC с 2006 по 2013 г. объем отечественного рынка возрос до 7,7 млрд долл. [3]. На его рост не повлиял кризис 2008 г., в котором наблюдалось снижение темпов роста до 3,6 млрд долл., ИТ-рынок увеличивался и в 2011 г. достиг 5,94 млрд долл. Причина данного явления - тот факт, что крупными заказ- 
чиками отечественной IT-отрасли являются государство и компании с участием государства. При этом государство поддерживает российских создателей программного обеспечения, проводя льготную налоговую политику для них. Кроме того, государство стремится к балансу и обеспечению оговоренных отношений между органами власти, отраслевыми ассоциациями, ИТ-компаниями и экспертным сообществом. В течение последних лет наблюдается равномерное сокращение доли аппаратных средств и рост доли программного обеспечения в структуре IT-рынка. Однако в последнее время увеличилось число фирм, желающих разработать собственное программное обеспечение, что вызвано желанием крупных предприятий приобрести независимость от фирм-субподрядчиков и увеличить безопасность информационного функционирования предприятия. Соответственно продажи технического оборудования выросли незначительно,т.к. компании стремятся к более долговременной эксплуатации технических средств, что объясняется нерациональностью постоянных закупок нового оборудования.

В настоящее время рынок IT-услуг поддерживают долгосрочные государственные проекты, а также проекты, которые направлены на повышение конкурентоспособности, в первую очередь, в банковской, телекоммуникационной и розничной сферах. Однако российский рынок информационных технологий развивается неравномерно и по прогнозам аналитиков до 2018 г. затраты компаний на информационные технологии будут повышаться на 6-8 \% каждый год [1].

Наблюдается рост спроса на различные «умные устройства» и интернет-сервисы, внедрение новых систем управления как в частных, так и в государственных организациях. В связи с тем, что в последнее время резко возросло количество смартфонов и планшетных компьютеров, увеличивается и объем программного обеспечения для мобильных устройств. Нельзя также оставить без внимания и максимальный темп роста «облачных сервисов». Несмотря на то, что они занимают сегодня сравнительно небольшую долю на рынке, которая в 2013 г. составила 3,7 \%, они уже пользуются повышенным спросом у потребителей IT-услуг. Услуги информационного характера являются динамичной сферой рынка услуг, который активно способствует росту ВВП и конкурентоспособности России. Достижение целей социально-экономического развития тесно связано с распространением информационно-коммуникационных технологий. На макроэкономическом уровне их применение поднимает уровень конкурентности рынков и ведет к повышению экспертной оценки инвестиционной привлекательности национальной экономики.

На микроэкономическом уровне результативное употребление ИКТ вынуждает организации более целесообразно использовать существующие у них ресурсы и увеличивать конкурентоспособность, а также совершенствовать экономические показатели, повышая их инвестиционную привлекательность. За счет устойчивого роста информационных потоков стремительно моделируются, меняются и обновляются имеющиеся производственные системы.

Что же касается формирования информационно-коммуникационных технологий, а также их влияния на изменение уровня и качества жизни населения в целом, то можно предположить, что оно будет проявляться в следующем.

1. Уменьшение уровня безработицы путем организации новых рабочих мест в ИКТ-секторе, а также в иных отраслях национальной экономики;

2. Рекомбинация доходов путем денежных переводов между субъектами различных государств, а также трудовыми миграциями в границах обусловленного государства из более развитых в менее развитые в экономическом плане территориальные образования;

3. Увеличение доходов работников ИКТсектора приведет к увеличению их расходов на товары и услуги, что в свою очередь подействует на формирование новых рабочих мест в области услуг и будет влиять положительно на динамику развития национальной экономики;

4. Понижение трансакционных издержек на приобретение товаров и услуг;

5. Увеличение свободного времени за счет рационализации системы управления и совершения сделок купли-продажи при помощи ИКТ.

Данные инновации несомненно приведут к росту уровня жизни не только работников ИКТ, но и членов их семей, а также к росту уровня образования и квалификации. Это в свою очередь повлечет увеличение стоимости их рабочей силы.

Таким образом, современные информационно-коммуникационные технологии - это весьма востребованный продукт для организации налаженной работы и продвижения бизне- 
са, эффективное владение которым дает конкурентное преимущество в бизнес-среде. Сегодня трудно представить предприятие любой сферы деятельности, которое бы не имело сайта или портала, электронных площадок Интернета или не использовало электронного маркетинга.

В рамках стратегии инновационного развития многие отечественные предприятия постоянно разрабатывают или улучшают новейшие продукты, процессы, технологии и жестко конкурируют, стремясь достичь максимального доверия клиентов путем внедрения передовых технологий в сфере обслуживания. Всё это помогает им уменьшать издержки производства и приобретать большую прибыль в сфере развития информационных технологий.

В настоящее время в России информационные технологии занимают существенную роль в бизнес-деятельности компаний. Однако компании пока не ставят перед ИТслужбами цель повышения роста бизнеса компании в отличие от зарубежных. Ключевыми целями отечественных компаний являются рост производительности и прибыли, а также оптимизация расходов. И только одна пятая российских компаний в итоге развития ИТ рассчитывает на выход компании на новые рынки и создание новых товаров и услуг; еще меньшее их число связывает создание новых конкурентных преимуществ с развитием информационных технологий.

По итогам исследования Gartner видно, что только треть компаний всё еще рассматривает ИТ в качестве служебного инструмента, остальные же компании уже осмыслили значимость информационных технологий в достижении бизнес-целей и организации конкурентных преимуществ.

Аутсорсинг является основополагающим средством и методом для роста информационных технологий. Анализируя исследования Ассоциации стратегического аутсорсинга ACTPA, можно отметить, что коммерческий рынок IT-аутсорсинга в России в 2011 г. значительно расширился и практически составил \$1,3 млрд, что составляет приблизительно 0,5 \% от общего мирового рынка ИТ-аутсорсинга, который в свою очередь равен 254 млрд долл. (по данным Forrester Research) [5] .

Самые распространенными видами услуг 2017 отечественного аутсорсинга являются поддержка IT-инфраструктуры - 20,4 \% объема общего рынка и аутсорсинг услуг Центров обработки данных (ЦОД) - 18,8\%.

Главными пользователями стали органы государственной власти, силовые структуры, нефтегазовая отрасль, ИТК-кластер. Сдерживающим фактором развития IT-аутсорсинга в России являются незнание организациями всех плюсов и преимуществ перехода на удаленное обслуживание, а также их нежелание заменить имеющуюся модель работы на новую. Главным мотивом инициативных пользователей IT-аутсорсинга является оптимизация затрат. Нужно отметить, что существуют компании, где экономия достигает 50 \%. По прогнозам ИХ «Финам», OptimaServices и ряда IT- и бизнес-аналитиков, аутсорсинг является ключевой программой увеличения рынка информационных технологий в России. Реальной возможностью сейчас обладает сегмент услуг Центров обработки данных (ЦОД). «Вырабатывание» европейского и американского рынков ЦОД понемногу тормозится, а «новичок» глобального рынка - это российский сегмент, который демонстрирует быстрый темп роста. Согласно показателям исследования CNewsAnalytics в 2011 г. объем российского рынка ЦОД увеличился на 27 \% и достиг 178,5 млн долл. [4]. На момент исследования 2/3 дата - центров России расположены в г. Москве и Московской области, здесь же сосредоточено и набольшее количество потребителей услуг коммерческих ЦОД. По мнению автора, быстрыми темпами рынок дата-центров будет развиваться прежде всего в регионах.

Следует отметить и тот факт, что с развитием компетенции заказчиков и их требований к IT-инфраструктуре увеличится доля ЦОД с максимальной степенью надежности - TierIII и выше. При этом важнейшим катализатором роста услуг IT-аутсорсинга ЦОД будет экономический аспект: компании не включают в свой бюджет большие расходы на строительство собственного ЦОДа, достаточно крупные эксплуатационные затраты на обслуживание и др. Значительная часть руководителей компаний придет к осознанию превосходства профессионального аутсорсингового ЦОД, т.к. примером его эффективного использования будут крупнейшие компании страны, регионов, республик, а также правительственные учреждения, которые доверили хранение информационных данных «облакам».

Одной из наиболее перспективных конкурентных сфер российского ИТ-бизнеса являютс «Облачные» вычисления в информатике, представляющие собой модель предоставления повсеместного и благоприятного сетевого доступа по запросу к общему пулу конфигурируемых вычислительных ресурсов (например, 
сетям передачи данных, серверам, устройствам хранения данных, приложениям и сервисам), оперативно предоставленных и высвобожденных с низкими эксплуатационными расходами и обращениями к провайдеру.

Другой сферой, имеющий значительный потенциал роста, является использование поисковых и навигационных систем. Это связано с уникальными шансами и рисками, характерными для российского рынка. Благодаря сложности русского языка местные компании, прежде всего, Яндекс, господствуют на российском рынке поисковых систем (Google занимает на этом рынке второе место, причем с внушительным отставанием), а запуск спутников “ГЛОНАСС” - российского аналога GPS придал дополнительный импульс разработке навигационных систем. Государственные инвестиции в ИТ, а также закон о защите персональных данных привели к росту спроса на ИТ-сервисы и продукты. При этом российский рынок остается в значительной степени ориентированным на корпоративного заказчика.

«Облачные» компьютерные технологии благодаря существующим возможностям приобретают всё более важное значение для предприятий, а именно, разрешают пользователям через Интернет и иные цифровые сети получать доступ к масштабируемому и гибкому набору ресурсов хранения информации, а также к реализации компьютерных операций по мере необходимости. Таким образом, в связи с быстрым развитием информационных технологий, в ближайшие два десятилетия «облачные» технологии станут одними из наиболее значимых прорывных технологий, которые окажут большое воздействие на формирование рынка, экономики и общества в целом. Рассмотрим их подробнее.

В последнее время стало модным понятие виртуальные «облака», продвигающееся в сфере автоматизации и виртуализации IT- процессов. Быстрое развитие возможности хранения, обработки, а также процесса передачи данных стало фундаментом для экономики «облачных» технологий. «Облачные» вычисления (cloud computing) - это результат эволюции информационных технологий в бизнесе, выступающих в виде технологии, разрешающих осуществлять взаимодействие физического оборудования, сетей, мощностей для хранения, услуг и интерфейсов, нужных для оказания компьютерных технологий в виде услуг.

«Облачные» сервисы имеют пять главных характеристик: самообслуживание по запросу, всесторонний доступ к сети, концентрация ресурсов, легкость и учет потребления.
При этом существует три модели обслуживания рынка «облачных» услуг, которые не совсем сочетаются с существующими ИТ-категориями, где аналитические компании уже привыкли измерять сегменты ИТ-рынка:

1. Software as a Service, SaaS (программное обеспечение как услуга);

2. Platform as a Service, PaaS (платформа как услуга);

3. Infrastructure as a Service, IaaS (инфраструктура как услуга).

«Облачные» технологии в настоящее время являются платформой для перехода к e-governance (электронному правительству), межведомственной кооперации и инновациям на всех уровнях, что подтверждается глобальными решениями в сфере ИКТ крупнейших стран мира.

В настящий момент разработке продуманной IT-стратегии и введению новых IT-проектов необходимое внимание уделяют далеко не все предприятия. Но, стоит отметить, что в условиях сильной конкуренции на рынке без создания собственных информационных технологий не обойтись. Обязательным условием успешного функционирования бизнеса является многообразие ассортимента продукции и динамичность ее сопровождения. Современные условия требуют от предприятия стремительности реакции на изменяющуюся ситуацию, в которой качество и особенность обслуживания становятся ключевым критерием их успешности. Предприятия с высоким качеством обслуживания и широко применяющимися информационными технологиям занимают главенствующее положение в бизнесе даже при условии того, что главным для клиента является ценовые позиции.

Вопрос повышения конкурентоспособности фирм в теории и мировой практике обычно рассматривается в аспекте повышения качества производимых фирмами товаров и услуг и/или совершенствования бизнес-процессов. Несмотря на то, что в последние два десятилетия развитие информационных технологий происходило стремительными темпами, система их внедрения, использования и модернизации в фирмах далека от совершенства, особенно на предприятиях традиционных отраслей экономики (таких как агропромышленные хозяйства, предприятия розничной торговли и дистрибуции, пищевые, текстильные, мебельные производства и т.д.).

Необходимо установление «информационного моста» с традиционными фирмами, не просто распространение информации, но и получение обратной связи с использовани- 
ем современных технологий. Установив эту связь, сделав ее систематической и непрерывной, высокотехнологичные фирмы могут сделать следующий шаг - придать информационным технологиям новое значение, объединив высокие технологии и традиционные товары и услуги. Информационные технологии позволяют усиливать конкурентоспособность, создавая связи не только внутри фирм или между фирмами/отраслями, но и устанавливая взаимодействие с важной конкурентной силой - потребителями.

Несмотря на то, что информационные технологии востребованы, и в дальнейшем их востребованность, несомненно, будет расти, компаниям следует внедрять новые ИТ-решения как в процесс формирования качества продуктов и оказания услуг с целью удержания конкурентных позиций на рынке и в сфере управления бизнесом. Тем или иным способом фирма должна продвигаться к наиболее перспективным информационным технологиям, обеспечивающим максимальную производительность труда и устойчивые конкурентные преимущества.

Развитие бизнеса, продвижение и осуществление различных материальных и нематериальных баз напрямую зависит от внедрения информационных технологий. Предусмотрено много программных продуктов, направленных на оптимизацию бизнес-процессов, повышения контроля над множеством документов, необходимых для ведения и контроля внутренней документации. Информационные технологии дают возможность обмениваться информацией на беспредельно больших расстояниях, одновременно заниматься бизнесом и развивать его в различных точках мира. В заключении можно констатировать, что благодаря информационным технологиям имеется возможность неограниченного расширения бизнеса при максимальной автоматизированности процесса управления.

\section{СПИСОК ЛИТЕРАТУРЫ}

1. Белов Ю. В российских ИТ задумываются о кризисе // Cnews.ru: сайт аналитического агенства Cnews Analytics. 2013. - URL: http:// www.cnews.ru/reviews/new/rynok_it_itogi_2012/ articles/rynok_it_v_rossii_perehodit_k_sderzhannomu_rostu/.

2. Глобальные информационные технологии: отчет Всемирного экономического форума (2014 г.). - URL: http://www.weforum.org/gitr.

3. Данные агентства CNews Analytics. - URL: http://www.cnews.ru/reviews/free/.

4. Данные компании Forrester Research. URL: http:// www.forrester.com.

5. Обзор РБК. IT для бизнеса Рынок IT-услуг // cinimex.ru. 2014. - URL: http://www. cinimex.ru/press-center/publications/obzor-rbk-itdlya-biznesa/.

6. Устинова Н.Г. Влияние институциональных факторов на инновационную составляющую экономики // Вестник СГСЭУ. - 2015. - № 5. С. 59-61.

7. Яковенко Н.А., Анфиногентова А.А., Ермолова О.В. Условия и факторы реализации стратегических приоритетов в агропродовольственном комплексе России // Аграрный научный журнал. - 2015. - №11. - С. 97-100.

Ромашкин Тимур Владимирович, канд. экон. наук, доцент кафедры «Экономическая теория и нацииональная экономика», Саратовский национальный государственный университет имени Н.Г. Чернышевского. Россия.

410012, г. Саратов, ул. Астраханская, 83.

Тел.: 89271236383.

Ключевые слова: информация; инновации; информационные ресурсы; информационный рынок; информаицонные технологии; бизнес-компании; бизнес-среда.

\section{INFORMATIONAL SUPPORT OF BUSINESS IN MODERN CONDITIONS}

Romashkin Timur Vladimirovich, Candidate of Economic Sciences Associate Professor of the chair "Economic Theory and National Economy", Saratov National State University named after N.G. Chernyshevsky. Russia.

Keywords: information; innovations; information resources; information markets; information technology; business; business environment.

The article analyzes one of the most pressing issues of business, namely, the information component of the business. Scope of business in modern conditions, is a central and essential sector in terms of the information market. The purpose of the article is to consider information support of Russian business realitv. It is noted that the information in the electronic registration is an important component of the market infrastructure. It is proved that the lack of development of infrastructure of the information service business in Russia shows the immaturity of the Russian business, the lack of analytical work and, consequently, low competitiveness. They are identified barriers of the Russian IT market development. They are obtained competitive promising sphere of Russian IT business; they are offered directions of improvement of the technology business. Conceptual issues and conclusions enrich the theory of the information market and allow forming effective tools for the implementation of information support of business with a view to its' sustainable development. 